\title{
Phytotoxin sorption to clay minerals
}

\author{
Carina D. Schönsee ${ }^{1,2}$, Felix E. Wettstein ${ }^{1}$ and Thomas D. Bucheli ${ }^{1 *}$ (B)
}

\begin{abstract}
Background: Phytotoxins of various classes and origin are often found in their cationic form in the soil environment and thus, their overall soil behavior may be strongly affected by all geosorbents presenting cation exchange capacity (CEC). In addition to soil organic carbon (SOC), clays may exhibit great potential as sorbents for cationic organic chemicals. Therefore, 52 compounds of the major phytotoxin classes alkaloids, terpenoids and steroids were investigated with regard to their sorption behavior to the clay minerals kaolinite (low CEC) and montmorillonite (high CEC) by means of continuous flow column sorption experiments as a high-throughput alternative to traditional batch sorption experiments.

Results: In total, sorption coefficients $\log D_{\text {clay }}\left[\mathrm{L} \mathrm{kg}^{-1}\right]$ were quantifiable for 26 phytotoxins on kaolinite ( $\left.\log D_{\text {clay }}>0.1\right)$ and 33 on montmorillonite (log $D_{\text {clay }}>0.5$ ). They ranged from $0.14 \pm 0.09$ for the pyrrolizidine alkaloid senkirkine on kaolinite to $3.05 \pm 0.03$ for the indole alkaloid brucine on montmorillonite. Although maximum sorbed concentrations lay well below the CEC for both clay minerals, sorption non-linearity was observed in some cases where as little as $0.1 \%$ of all cation exchange sites were occupied. Contrary to the expectations, sorption non-linearity could not be wholly explained by saturation of available sorption sites; for protonated tertiary amines with aromatic moieties, cooperative sorption seemingly took place and the results indicated a significant increase in sorption affinities within a very limited concentration range. Comparing montmorillonite and SOC, notable differences in preferences of cationic sorbates were observed between phytotoxins with and without aromatic moieties (e.g., isoquinoline versus pyrrolizidine alkaloids) as well as between $\mathrm{N}$-heterocycles and $\mathrm{N}$-heteroaromatics in particular (e.g., strychnine versus gramine; both indole alkaloids).
\end{abstract}

Conclusions: Overall, clay sorption seems a result of the interplay of charge location on the sorbent and various structural features of the sorbates. To confirm observed tendencies towards cooperative sorption for certain cationic phytotoxins, further studies with higher concentrations are needed. Nevertheless, obtained sorption coefficients indicate that a high proportion of phytotoxin sorption in soils may be attributed to clay minerals. Thus, clay minerals possess the ability to decrease total cationic phytotoxin environmental mobility.

Keywords: Natural toxins, Aluminosilicates, Montmorillonite, Kaolinite, Freundlich isotherm, Cooperative sorption, Environmental mobility

\section{Background}

A tremendous number of structurally different secondary metabolites are produced by plants $[1,2]$ and subsequently emitted to environmental compartments such

\footnotetext{
*Correspondence: thomas.bucheli@agroscope.admin.ch

${ }^{1}$ Environmental Analytics, Agroscope, Reckenholzstrasse 191, 8046 Zürich, Switzerland

Full list of author information is available at the end of the article
}

as air, soil and water. Among other functions, they can seemingly serve as signal molecules for, e.g., pollinators or as defense compounds (phytotoxins) against, e.g., pathogens or insects. As such, they are important for the plants' survival [3]. Phytotoxins are biologically active and may also pose a risk to non-target organisms [4-6]. As "nature's own pesticides" [4], phytotoxins are also used as biopesticides [7, 8] or serve as model compounds for the development of such chemicals [9]. Many phytotoxins are protonated under environmentally relevant
Springer Open

(c) The Author(s) 2021, corrected publication 2021. This article is licensed under a Creative Commons Attribution 4.0 International License, which permits use, sharing, adaptation, distribution and reproduction in any medium or format, as long as you give appropriate credit to the original author(s) and the source, provide a link to the Creative Commons licence, and indicate if changes were made. The images or other third party material in this article are included in the article's Creative Commons licence, unless indicated otherwise in a credit line to the material. If material is not included in the article's Creative Commons licence and your intended use is not permitted by statutory regulation or exceeds the permitted use, you will need to obtain permission directly from the copyright holder. To view a copy of this licence, visit http://creativecommons.org/licenses/by/4.0/. 
conditions; particularly alkaloids, which are produced by $10-20 \%$ of all higher plants [1], are often found in their cationic form in environmental compartments. While organic carbon is recognized to predominately affect any organic compound's phase distribution in soils, clays are one of the major geosorbents in soils and sediments exhibiting potential for sorption of cationic organic chemicals in particular $[10,11]$. As demonstrated in a preceding study, sorption of the majority of investigated alkaloids to soil organic carbon (SOC) is dominated by cation exchange processes on negatively charged functional groups [12]. Electrostatic interactions such as cation exchange and sorption to geosorbents other than SOC are rarely integrated in soil sorption models commonly used in environmental exposure assessment. Thus, these models often underestimate sorption of cationic chemicals in soils [13]. However, a model that was specifically developed for cationic organic chemicals suggests that in some cases more than $90 \%$ of a cation's overall sorption affinity can be attributed to clay minerals $[10,14]$. As an illustrative example, sorption of the indole alkaloid strychnine (STY, base $p K_{a}=8.37$ ) was previously observed to directly correlate with soil clay content rather than with SOC content [15]. In combination, these results highlight the fact that the role of clay minerals in determining the phase distribution of protonated phytotoxins and their mobility in soil may be substantially undervalued.

For SOC, we obtained systematic sorption data for 51 largely protonated $\mathrm{N}$-containing phytotoxins as well as 41 neutral or deprotonated compounds. Thus, we were able to pinpoint structural moieties majorly affecting phytotoxin sorption behavior by using continuous flow column sorption experiments as a high-throughput alternative to traditional batch sorption experiments [12]. The aim of this study was to (1) quantify sorption affinities of a selection of these previously investigated phytotoxins to the two common clay minerals kaolinite and montmorillonite by applying the same methodology as in our previous study; (2) gain further insights into how phytotoxin structural features affect sorbate-sorbent interactions, and (3) compare phytotoxins' sorption affinities to model clay with those to model SOC as a basis to evaluate the relative importance of these major geosorbents in soils.

\section{Experimental section}

\section{Sorbates, sorbents and solutions}

A set of 52 phytotoxins previously studied with regard to their sorption behavior to SOC [12] was chosen to investigate sorption to clay minerals under environmentally relevant conditions. Selected sorbates were representatives of the major phytotoxin classes alkaloids, terpenoids or steroids and were investigated as predominantly protonated or neutral species (Table 1, Additional file 1: Table S2). While for the protonated sorbates (i.e., $60 \%$ of investigated compounds) cation exchange was identified as the major sorption mechanism to SOC, sorption of the chosen neutral compounds was dominated by either hydrophobic partitioning or complexation reactions.

Stock solutions of phytotoxins (Phytolab, Vestenbergsgreuth, Germany or Sigma-Aldrich, Buchs, Switzerland) as well as solutions of sodium nitrate $\left(\mathrm{NaNO}_{3}\right)$ and thiourea $\left(\mathrm{CH}_{4} \mathrm{~N}_{2} \mathrm{~S}\right.$, both Sigma-Aldrich) as conservative tracers were prepared in methanol (HPLC grade, SigmaAldrich) and stored at $-20{ }^{\circ} \mathrm{C}$. Aqueous eluents used in retention measurements were prepared by dissolving calcium chloride $\left(\mathrm{CaCl}_{2} \times \mathrm{H}_{2} \mathrm{O}\right.$, Sigma-Aldrich) in ultrapure water (Milli-Q system, Merck Millipore, Darmstadt, Germany) to get a solution of $5 \mathrm{mM} \mathrm{CaCl}_{2}$, and air-equilibrated for at least $24 \mathrm{~h}$ to reach a stable $\mathrm{pH}$ of $6 \pm 0.1$. Phytotoxin test solutions for sorption experiments (0.01$20 \mathrm{mg} \mathrm{L}^{-1}$ ) were prepared by dilution with the aqueous eluent while ensuring that the methanol concentration remained below $2 \%$ in all cases.

Two clay minerals with different cation exchange capacity (CEC) were purchased from The Clay Minerals Society (Chantilly, USA): The non-expandable two-layer clay kaolinite with a CEC of $20 \mathrm{mmol} \mathrm{kg}^{-1}$, a surface area of $10.05 \pm 0.02 \mathrm{~m}^{2} \mathrm{~g}^{-1}$ and $5 \%$ permanent charge; and the expandable, three-layer clay montmorillonite with a CEC of $844 \mathrm{mmol} \mathrm{kg}^{-1}$, a surface area of $83.79 \pm 0.22 \mathrm{~m}^{2} \mathrm{~g}^{-1}$, $95 \%$ permanent charge and $\mathrm{Ca}^{2+}$ as major exchange cation [16]. Both clays were sieved to obtain a homogenous particle size of 32-63 $\mu \mathrm{m}$ (stainless steel sieves ISO 33101, RETSCH, Haan, Germany).

\section{Continuous flow column sorption experiments}

Sorption affinities of phytotoxins to clay minerals were determined by continuous flow column sorption experiments using manually packed HPLC columns [12]. This approach was shown to be directly comparable to traditional batch sorption experiments on numerous occasions [17, 18]. Empty HPLC columns (stainless steel, length $14 \mathrm{~mm}$, inner diameter $3 \mathrm{~mm}$ ) and additional equipment (pre-columns, connecting nuts, stainless steel sieves of $3 \mu \mathrm{m}$ pore size, glass fiber filters of $<1.5 \mu \mathrm{m}$ pore size and PTFE sealing rings) were purchased from Bischoff Chromatography (distributed by WICOM International AG, Maienfeld, Switzerland). Clay was diluted with silicon carbide ( $\mathrm{SiC}$, particle size 10.8-13.3 $\mu \mathrm{m}$, ESK-SiC, Frechen, Germany) as quasi-inert material to obtain stationary phases with $1 \%$ (montmorillonite) or $20 \%$ (kaolinite, $\mathrm{w} / \mathrm{w})$ clay in respective columns. The column packing method, further modified from literature [19], is described in detail in Schönsee et al. [12] In short, the material mixture was packed into the empty columns and 
Table 1 List of analyzed phytotoxins including their respective charge under experimental conditions

\begin{tabular}{|c|c|c|c|c|c|}
\hline$\overline{I D}$ & Toxin name & Toxin class & Sum formula & CAS & Charge at $\mathrm{pH} 6^{\mathrm{a}}$ \\
\hline AlL & Ailanthone & Terpenoid & $\mathrm{C}_{20} \mathrm{H}_{24} \mathrm{O}_{7}$ & $981-15-7$ & o \\
\hline ANI & Anisatin & Terpenoid & $\mathrm{C}_{15} \mathrm{H}_{20} \mathrm{O}_{8}$ & $5230-87-5$ & o \\
\hline BAC & Baccatin III & Terpenoid & $\mathrm{C}_{31} \mathrm{H}_{38} \mathrm{O}_{11}$ & $27548-93-2$ & o \\
\hline $\mathrm{BIC}$ & (+)-Bicuculline & Alkaloid & $\mathrm{C}_{20} \mathrm{H}_{17} \mathrm{NO}_{6}$ & $485-49-4$ & + \\
\hline BRU & Brucine & Alkaloid & $\mathrm{C}_{23} \mathrm{H}_{26} \mathrm{~N}_{2} \mathrm{O}_{4}$ & $357-57-3$ & + \\
\hline CAF & Caffeine & Alkaloid & $\mathrm{C}_{8} \mathrm{H}_{10} \mathrm{~N}_{4} \mathrm{O}_{2}$ & $58-08-2$ & o \\
\hline CEV & Cevadine & Alkaloid & $\mathrm{C}_{32} \mathrm{H}_{49} \mathrm{NO}_{9}$ & $62-59-9$ & + \\
\hline $\mathrm{CIN}$ & Cinobufagin & Steroid & $\mathrm{C}_{26} \mathrm{H}_{34} \mathrm{O}_{6}$ & $470-37-1$ & o \\
\hline COL & Colchicine & Alkaloid & $\mathrm{C}_{22} \mathrm{H}_{25} \mathrm{NO}_{6}$ & $64-86-8$ & o \\
\hline CON & Convallatoxin & Steroid & $\mathrm{C}_{29} \mathrm{H}_{42} \mathrm{O}_{10}$ & $508-75-8$ & o \\
\hline $\cos$ & (+)-Costunolide & Terpenoid & $\mathrm{C}_{15} \mathrm{H}_{20} \mathrm{O}_{2}$ & $553-21-9$ & o \\
\hline CUE & Cucurbitacin E & Terpenoid & $\mathrm{C}_{32} \mathrm{H}_{44} \mathrm{O}_{8}$ & $18444-66-1$ & o \\
\hline CYT & (-)-Cytisine & Alkaloid & $\mathrm{C}_{11} \mathrm{H}_{14} \mathrm{~N}_{2} \mathrm{O}$ & $485-35-8$ & + \\
\hline$D A B$ & 10-Deacetylbaccatin III & Terpenoid & $\mathrm{C}_{29} \mathrm{H}_{36} \mathrm{O}_{10}$ & $32981-86-5$ & o \\
\hline DIG & Digitoxigenin & Steroid & $\mathrm{C}_{23} \mathrm{H}_{34} \mathrm{O}_{4}$ & $143-62-4$ & o \\
\hline $\mathrm{ECH}$ & Echimidine & Alkaloid & $\mathrm{C}_{20} \mathrm{H}_{31} \mathrm{NO}_{7}$ & $520-68-3$ & + \\
\hline ERU & Erucifoline & Alkaloid & $\mathrm{C}_{18} \mathrm{H}_{23} \mathrm{NO}_{6}$ & $40158-95-0$ & +10 \\
\hline ERUNO & Erucifoline N-oxide & Alkaloid & $\mathrm{C}_{18} \mathrm{H}_{23} \mathrm{NO}_{7}$ & 123864-94-8 & \\
\hline GAL & Galanthamine & Alkaloid & $\mathrm{C}_{17} \mathrm{H}_{21} \mathrm{NO}_{3}$ & $357-70-0$ & + \\
\hline GEL & Gelsemine & Alkaloid & $\mathrm{C}_{20} \mathrm{H}_{22} \mathrm{~N}_{2} \mathrm{O}_{2}$ & 509-15-9 & + \\
\hline GRA & Gramine & Alkaloid & $\mathrm{C}_{11} \mathrm{H}_{14} \mathrm{~N}_{2}$ & $87-52-5$ & + \\
\hline HEL & Heliotrine & Alkaloid & $\mathrm{C}_{16} \mathrm{H}_{27} \mathrm{NO}_{5}$ & $303-33-3$ & + \\
\hline HOR & Hordenine & Amine & $\mathrm{C}_{10} \mathrm{H}_{15} \mathrm{NO}$ & 539-15-1 & + \\
\hline ISC & (+)-Isocorydine & Alkaloid & $\mathrm{C}_{20} \mathrm{H}_{23} \mathrm{NO}_{4}$ & $475-67-2$ & +10 \\
\hline$J A C$ & Jacobine & Alkaloid & $\mathrm{C}_{18} \mathrm{H}_{25} \mathrm{NO}_{6}$ & $6870-67-3$ & +10 \\
\hline LAS & Lasiocarpine & Alkaloid & $\mathrm{C}_{21} \mathrm{H}_{33} \mathrm{NO}_{7}$ & $303-34-4$ & + \\
\hline LASNO & Lasiocarpine $\mathrm{N}$-oxide & Alkaloid & $\mathrm{C}_{21} \mathrm{H}_{33} \mathrm{NO}_{8}$ & $127-30-0$ & \\
\hline LAT & Lathyrol & Terpenoid & $\mathrm{C}_{20} \mathrm{H}_{30} \mathrm{O}_{4}$ & $34420-19-4$ & o \\
\hline LYC & Lycopsamine & Alkaloid & $\mathrm{C}_{15} \mathrm{H}_{25} \mathrm{NO}_{5}$ & 10285-07-1 & + \\
\hline LYO & Lycorine & Alkaloid & $\mathrm{C}_{16} \mathrm{H}_{17} \mathrm{NO}_{4}$ & $476-28-8$ & $+/ 0$ \\
\hline MAT & Matrine & Alkaloid & $\mathrm{C}_{15} \mathrm{H}_{24} \mathrm{~N}_{2} \mathrm{O}$ & $519-02-8$ & + \\
\hline MON & Monocrotaline & Alkaloid & $\mathrm{C}_{16} \mathrm{H}_{23} \mathrm{NO}_{6}$ & $315-22-0$ & $+/ 0$ \\
\hline NIC & Nicotine & Alkaloid & $\mathrm{C}_{10} \mathrm{H}_{14} \mathrm{~N}_{2}$ & $65-31-6$ & + \\
\hline NUC & (-)-Nuciferine & Alkaloid & $\mathrm{C}_{19} \mathrm{H}_{21} \mathrm{NO}_{2}$ & $475-83-2$ & + \\
\hline OLE & Oleandrin & Steroid & $\mathrm{C}_{32} \mathrm{H}_{48} \mathrm{O}_{9}$ & $465-16-7$ & o \\
\hline PAR & Parthenolide & Terpenoid & $\mathrm{C}_{15} \mathrm{H}_{20} \mathrm{O}_{3}$ & 20554-84-1 & o \\
\hline PIC & Picrotoxinin & Terpenoid & $\mathrm{C}_{15} \mathrm{H}_{16} \mathrm{O}_{6}$ & $17617-45-7$ & o \\
\hline PIL & Pilocarpine & Alkaloid & $\mathrm{C}_{11} \mathrm{H}_{16} \mathrm{~N}_{2} \mathrm{O}_{2}$ & $54-71-7$ & + \\
\hline PRO & Protopine & Alkaloid & $\mathrm{C}_{20} \mathrm{H}_{19} \mathrm{NO}_{5}$ & $130-86-9$ & + \\
\hline PTB & Pterosin B & Terpenoid & $\mathrm{C}_{14} \mathrm{H}_{18} \mathrm{O}_{2}$ & $34175-96-7$ & o \\
\hline QUI & (-)-Quinine & Alkaloid & $\mathrm{C}_{20} \mathrm{H}_{24} \mathrm{~N}_{2} \mathrm{O}_{2}$ & $130-95-0$ & + \\
\hline REC & Retronecine & Alkaloid & $\mathrm{C}_{8} \mathrm{H}_{13} \mathrm{NO}_{2}$ & $480-85-3$ & + \\
\hline RET & Retrorsine & Alkaloid & $\mathrm{C}_{18} \mathrm{H}_{25} \mathrm{NO}_{6}$ & $480-54-6$ & $+/ 0$ \\
\hline SAT & a-Santonin & Terpenoid & $\mathrm{C}_{15} \mathrm{H}_{18} \mathrm{O}_{3}$ & 481-06-1 & o \\
\hline SEK & Senkirkine & Alkaloid & $\mathrm{C}_{19} \mathrm{H}_{27} \mathrm{NO}_{6}$ & $2318-18-5$ & +10 \\
\hline SEN & Senecionine & Alkaloid & $\mathrm{C}_{18} \mathrm{H}_{25} \mathrm{NO}_{5}$ & $130-01-8$ & +10 \\
\hline SENNO & Senecionine $\mathrm{N}$-oxide & Alkaloid & $\mathrm{C}_{18} \mathrm{H}_{25} \mathrm{NO}_{6}$ & $13268-67-2$ & \\
\hline SOP & Sophocarpine & Alkaloid & $\mathrm{C}_{15} \mathrm{H}_{22} \mathrm{~N}_{2} \mathrm{O}$ & $6483-15-4$ & + \\
\hline STR & Strophanthidin & Steroid & $\mathrm{C}_{23} \mathrm{H}_{32} \mathrm{O}_{6}$ & $66-28-4$ & o \\
\hline STY & (-)-Strychnine & Alkaloid & $\mathrm{C}_{21} \mathrm{H}_{22} \mathrm{~N}_{2} \mathrm{O}_{2}$ & $57-24-9$ & + \\
\hline VIN & $(+)$-Vincamine & Alkaloid & $\mathrm{C}_{21} \mathrm{H}_{26} \mathrm{~N}_{2} \mathrm{O}_{3}$ & $1617-90-9$ & + \\
\hline $\mathrm{YOH}$ & Yohimbine & Alkaloid & $\mathrm{C}_{21} \mathrm{H}_{26} \mathrm{~N}_{2} \mathrm{O}_{3}$ & $146-48-5$ & + \\
\hline
\end{tabular}


Table 1 (continued)

a $\mathrm{o}=$ neutral at $\mathrm{pH} 6 ;+=$ protonated at $\mathrm{pH} 6\left(\right.$ base $\left.p K_{a}>6.5\right) ;+/ \mathrm{o}=$ partially protonated/partially neutral $\left(5.5<\right.$ base $\left.p K_{a}<6.5\right)$

exposed to a continuously increasing flow of the aqueous eluent in an Agilent HPLC 1260 system (Santa Clara, USA) for liquid compression. Columns packed with $\mathrm{SiC}$ only were prepared as reference columns. Preceding any measurement, each column was equilibrated at least overnight by flushing with the eluent at $0.1 \mathrm{~mL} \mathrm{~min}^{-1}$ to ensure that clay minerals were converted to the homoionic form with $\mathrm{Ca}^{2+}$ as major exchange cation. Signal intensities were acquired with diode array detection (DAD, Agilent 1290 DAD) at analyte-specific wavelengths (Additional file 1: Table S3). Measurements were generally executed at a flow rate of $0.1 \mathrm{~mL} \mathrm{~min}^{-1}$ and a fixed analysis temperature of $25 \pm 1{ }^{\circ} \mathrm{C}$. For all phytotoxins, $5 \mu \mathrm{L}$ of up to eight different dilutions of each individual sorbate were injected.

Using the continuous flow column sorption setup, quasi-equilibrium sorption coefficients $\left(D_{\text {clay }}\right)$ normalized to the amount of clay in the columns $\left(m_{\text {clay }}\right)$ can directly be derived from retention of the sorbates on the clay columns according to Eq. 1.

$$
D_{\text {clay }}\left[\mathrm{L} \mathrm{kg}^{-1}\right]=\left(V_{\text {ret,clay }}-V_{\text {ret, }, \mathrm{SiC}}\right) / m_{\text {clay }}
$$

with $\mathrm{V}_{\text {ret }}$ being the retention volume obtained by multiplying the dead-time corrected retention time of the sorbate with the constant flow rate of $0.1 \mathrm{~mL} \mathrm{~min}^{-1}$ for the clay and $\mathrm{SiC}$ column, respectively. To account for peak asymmetry resulting from pronounced tailing on the clay columns, primarily caused by the occurrence of various retention mechanisms at once (e.g., hydrophobic partitioning and cation exchange), all retention times were obtained based on the statistical first moment approach [20]. Experimentally derived sorption coefficients were further normalized to the CEC of the respective clay mineral $\left(D_{\mathrm{kao}, \mathrm{CEC}}, D_{\text {mont,CEC }}\right)$. Phytotoxin $D_{\mathrm{oc}}$ data, obtained under the same experimental conditions and also applying the column sorption setup [12], was normalized to the CEC of the organic reference material $\left(2130 \mathrm{mmol} \mathrm{kg}^{-1}\right)$ [21] to obtain $D_{\text {oc,CEC }}$ (Additional file 1: Table S1) for direct comparison with clay sorption affinities.

Semi-quantitative sorption isotherms with three to eight points were constructed analogous to similar previous studies for linearity testing [22]. The absorbance at the statistical first moment of the eluted peak was converted into the aqueous concentration at equilibrium $\left(c_{w}\left[\mathrm{mmol} \mathrm{L}^{-1}\right]\right)$ using an external calibration. Further, $c_{w}$ was multiplied with the corresponding $D_{\text {clay }}\left[\mathrm{L} \mathrm{kg}^{-1}\right]$ value to yield the sorbed concentration at equilibrium $\left(c_{s}\right.$ $\left.\left[\mathrm{mmol} \mathrm{kg}{ }^{-1}\right]\right)$. As sorption was expected to mainly occur on the clay surface or limited edge sites, isotherms were fitted with the Freundlich equation (Eq. 2) [23] defined as:

$$
c_{s}=K_{F} \times c_{w}^{n},
$$

where $K_{F}\left[\mathrm{mmol}^{1-n} \mathrm{~L}^{n} \mathrm{~kg}^{-1}\right]$ is the Freundlich coefficient and $n[-]$ the Freundlich exponent. The latter directly reflects sorption (non-)linearity. A Freundlich exponent of $n=1$ corresponds to linear sorption, while $n<1$ indicates saturation of available high affinity sorption sites. Exponents larger than one are typical for cooperative sorption with sorbate-sorbate in addition to sorbatesorbent interactions. Additional linear fitting was performed for comparison.

\section{Data quality}

Quality control measurements were executed as suggested by $\mathrm{Bi}$ et al. [24] and method performance was overall comparable with our preceding study on SOC [12]. Clay columns were firstly evaluated by assessing the retention factor $k$ of analytes at different flow rates between 0.025 and $0.15 \mathrm{~mL} \mathrm{~min}^{-1}$ (Additional file 1: Figure $\mathrm{S} 1$ ). The retention factor $k$ was calculated as follows:

$$
k[-]=\frac{\left(t_{R}-t_{0}\right)}{t_{0}},
$$

with $t_{R}$ being the retention time of the analyte, and $t_{0}$ the dead-time of the system (retention time of the nonretained tracer). Overall, variations in $k$ were negligible suggesting quasi-equilibrium conditions in the columns (Additional file 1: Figure S1). Sorbate recovery was tested by comparison of peak areas for the clay and $\mathrm{SiC}$ columns. For $82 \%$ of the phytotoxins, recoveries were in the range of $70-110 \%$ with a relative standard deviation of $16 \%$ and thus, considered sufficient (Additional file 1: Table S3). Any potential interactions of the sorbates with $\mathrm{SiC}$ and/or the whole HPLC system were assessed by measurements on the pure $\mathrm{SiC}$ column and were generally negligible with $t_{R}$ close to those of the non-retained tracers for all sorbates. Repeated measurements of the non-retained tracer $\mathrm{NaNO}_{3}$ and thiourea (Additional file 1: Figure S2) showed that column packing was very stable with retention time shifts smaller than $0.05 \mathrm{~min}$. In general, obtained sorption coefficients $D_{\text {clay }}$ were only valid if retention on the column was 50\% larger than the sum of the retention times of the tracer and analyte on 
the $\mathrm{SiC}$ only column. Additionally, all data for which retention on the clay column was below $30 \%$ of the tracer were discarded. These data quality criteria, adapted from literature [22], resulted in lower limits of $\log D_{\text {mont }} \sim 0.5$ and $\log D_{\text {kao }} \sim 0.1$ for the column setup. If sorbates did not pass both these criteria, sorption coefficients could not be quantified and are given as below the respective lower limit. No upper limit was defined as all tested phytotoxins were in the dynamic range of the method. The previously investigated alkaloid nicotine (NIC) showed an average $\log D_{\text {mont,CEC }}$ of $2.45 \pm 0.03$ which is in agreement with the literature value of $2.42 \pm 0.22$ for NIC sorption to clay minerals [11].

\section{Results and discussion}

Average values of experimentally derived sorption coefficients for the phytotoxins investigated in this study are given in Table 2 for both kaolinite $\left(\log D_{\text {kao }}\right)$ and montmorillonite $\left(\log D_{\text {mont }}\right)$. For kaolinite, 26 phytotoxins exceeded the quantification threshold of $0.1 \mathrm{log}$ units, while for montmorillonite, 33 had a sorption coefficient $>0.5$. Sorption of protonated phytotoxins to montmorillonite was, on a mass basis, on average $1.7 \log$ units stronger than to kaolinite. Neutral sorbates were poorly retained by any sorbent and rarely exceeded the quantification thresholds $\left(\log D_{\text {mont }}>0.5, \log D_{\text {kao }}>0.1\right)$ with retention being limited to the neutral alkaloids, colchicine $(\mathrm{COL})$ and caffeine $(\mathrm{CAF})$, as well as the steroid oleandrin (OLE) on montmorillonite and the steroid cinobufagin (CIN) on kaolinite. These results confirm the notion that clay minerals present geosorbents that are additionally relevant for the sorption of protonated chemicals in the soil environment, while neutral compounds are hardly affected [10]. The reason behind the retention of the abovementioned neutral sorbates onto one of the sorbents is not fully clear. Pronounced sorption of neutral $\mathrm{N}$-containing compounds to soils was described in previous studies and attributed to complexation to surface bound cations [25]. However, total soil distribution coefficients for neutral benzotriazole to different soils correlated with their respective SOC [25] but not clay content [26]. All four neutral phytotoxins mentioned above contain various keto-, ester- or acetylgroups. Those $\mathrm{H}$-donor and -acceptor functional groups may potentially be involved in interactions with the neutral polar domain of the aluminosilicates [10]. Albeit such functional groups are present in most of the other analyzed neutral phytotoxins as well, their sorption may just be less pronounced and below the operational limit of the method. Besides, the phytotoxins COL, CAF and CIN were among those sorbing strongest to SOC by nonspecific interactions [12]. Such non-specific interactions were shown to even contribute to sorption of cationic aromatic amines to montmorillonite [27]. Therefore, it is likely they occur for neutral sorbates as well.

\section{Sorption (non-)linearity}

The experimental results enabled the derivation of semi-quantitative sorption isotherms with three to eight concentration levels for 28 and 26 phytotoxins on montmorillonite and kaolinite, respectively. Isotherms for individual sorbates and compound classes on both clays are illustrated in the electronic supporting information (ESI, Additional file 1: Figure S3-S14). Estimated maximum sorbed concentrations lay more than a factor 100 below the CEC of montmorillonite and reached up to $3.3 \%$ coverage of cation exchange sites on kaolinite (Additional file 1: Table S4). The Freundlich equation fitted the experimental data very well, with average correlation coefficients $\left(\mathrm{R}^{2}\right)$ of 0.97 for montmorillonite (Table 3) and 0.99 for kaolinite (Table 4).

Sorption was observed to be largely linear for the majority of the phytotoxins on montmorillonite with an average $n$ of $1.09 \pm 0.08$ and equally good linear fit results (Table 3). Due to the very low maximum surface coverage reached within this study $(<0.3 \%)$, rather constant sorption affinities were expected for montmorillonite sorption in the investigated concentration range. However, exceptions were observed for the five protonated phytotoxins bicuculline (BIC), gramine (GRA), hordenine (HOR), nuciferine (NUC) and protopine (PRO) with Freundlich exponents in the range of 1.3 to 2.2 (Table 3). The differences in sorption isotherms in comparison with compounds displaying linear sorption on montmorillonite are visualized in Fig. 1 for the isoquinoline alkaloid PRO in contrast to the linearly sorbing pyrrolizidine alkaloid erucifoline (ERU). While $D_{\text {mont }}$ showed a relatively constant increase of $c_{s}$ as a function of $c_{w}$ for ERU, $D_{\text {mont }}$ of PRO increased markedly in the measured concentration range indicating a sigmoidal isotherm. For these isotherms, a plateau is generally expected at higher sorbent loads, which could not be evaluated in this study due to limited sorbate availability or solubility constraints at high concentrations. As $c_{s}$ differed markedly for the investigated sorbate set (maximum $c_{s}$ between $7 \times 10^{-5}$ and $2 \mathrm{mmol} \mathrm{kg}^{-1}$ ), one reason for why some sorbates showed $n>>1$ might simply be that the data reflected different parts of the isotherms (different levels of sorbed concentrations). Nonetheless, when comparing the isotherms of PRO and ERU, for which similar $\mathrm{c}_{\mathrm{s}}$ were evaluated, sorption non-linearity was rather pronounced for the former (Fig. 1). Thus, we cannot rule out that similar trends would be seen for all sorbates at substantially higher $c_{s}$ but we certainly observed variations in behavior for different compound classes at comparable $c_{s}$. 
Table 2 Mean sorption coefficients of phytotoxins to the clay minerals kaolinite and montmorillonite

\begin{tabular}{|c|c|c|c|c|}
\hline ID & $\log D_{\text {kao }}\left[\mathrm{L} \mathrm{kg}^{-1}\right]$ & $\log D_{\text {kao,CEC }}\left[\mathrm{L} \mathrm{mol}^{-1}\right]$ & $\log D_{\text {mont }}\left[\mathrm{L} \mathrm{kg}^{-1}\right]$ & $\log D_{\text {mont,CEC }}\left[\mathrm{L} \mathrm{mol}^{-1}\right]$ \\
\hline AlL & $<0.1$ & & $<0.5$ & \\
\hline ANI & $<0.1$ & & $<0.5$ & \\
\hline BAC & $<0.1$ & & $<0.5$ & \\
\hline $\mathrm{BIC}$ & $0.89 \pm 0.02(8)$ & $2.59 \pm 0.02$ & $2.82 \pm 0.19(4)$ & $2.90 \pm 0.19$ \\
\hline BRU & $1.09 \pm 0.11(8)$ & $2.79 \pm 0.11$ & $3.05 \pm 0.03(6)$ & $3.12 \pm 0.03$ \\
\hline CAF & $<0.1$ & & $2.08 \pm 0.01(4)$ & $2.15 \pm 0.01$ \\
\hline CEV & $0.94 \pm 0.07(4)$ & $2.64 \pm 0.07$ & $2.01 \pm 0.02(4)$ & $2.08 \pm 0.02$ \\
\hline $\mathrm{CIN}$ & $0.23 \pm 0.15(4)$ & $1.93 \pm 0.15$ & $<0.5$ & \\
\hline COL & $<0.1$ & & $2.07 \pm 0.02(4)$ & $2.14 \pm 0.02$ \\
\hline CON & $<0.1$ & & $<0.5$ & \\
\hline $\cos$ & $<0.1$ & & $<0.5$ & \\
\hline CUE & $<0.1$ & & $<0.5$ & \\
\hline CYT & $0.25 \pm 0.01(8)$ & $1.95 \pm 0.01$ & $2.13 \pm 0.01(4)$ & $2.21 \pm 0.01$ \\
\hline DAB & $<0.1$ & & $<0.5$ & \\
\hline DIG & $<0.1$ & & $<0.5$ & \\
\hline $\mathrm{ECH}$ & $0.16 \pm 0.01(8)$ & $1.86 \pm 0.01$ & $2.20 \pm 0.18(5)$ & $2.27 \pm 0.18$ \\
\hline ERU & $0.57 \pm 0.10(8)$ & $2.27 \pm 0.10$ & $2.70 \pm 0.06(10)$ & $2.77 \pm 0.06$ \\
\hline ERUNO & $<0.1$ & & $<0.5$ & \\
\hline GAL & $0.38 \pm 0.02(8)$ & $2.08 \pm 0.02$ & $2.98 \pm 0.01(4)$ & $3.05 \pm 0.01$ \\
\hline GEL & $<0.1$ & & $2.39 \pm 0.01(4)$ & $2.47 \pm 0.01$ \\
\hline GRA & $0.21 \pm 0.11(4)$ & $1.91 \pm 0.11$ & $2.01 \pm 0.08$ (4) & $2.08 \pm 0.08$ \\
\hline HEL & $<0.1$ & & $2.17 \pm 0.01(2)$ & $2.24 \pm 0.01$ \\
\hline HOR & $0.54 \pm 0.05(4)$ & $2.24 \pm 0.05$ & $2.10 \pm 0.08(4)$ & $2.17 \pm 0.08$ \\
\hline ISC & $0.89 \pm 0.05(8)$ & $2.59 \pm 0.05$ & $3.00 \pm 0.04$ (4) & $3.07 \pm 0.04$ \\
\hline$J A C$ & $0.97 \pm 0.07(8)$ & $2.67 \pm 0.07$ & $<0.5$ & \\
\hline LAS & $0.37 \pm 0.03(8)$ & $2.07 \pm 0.03$ & $2.44 \pm 0.19(8)$ & $2.51 \pm 0.19$ \\
\hline LASNO & $<0.1$ & & $1.19 \pm 0.01(2)$ & $1.26 \pm 0.01$ \\
\hline LAT & $<0.1$ & & $<0.5$ & \\
\hline LYC & $<0.1$ & & $1.77 \pm 0.01(2)$ & $1.84 \pm 0.01$ \\
\hline LYO & $<0.1$ & & $1.58 \pm 0.01$ & $1.65 \pm 0.01$ \\
\hline MAT & $0.75 \pm 0.12(8)$ & $2.45 \pm 0.12$ & $2.61 \pm 0.01$ & $2.68 \pm 0.01$ \\
\hline MON & $0.26 \pm 0.16(4)$ & $1.96 \pm 0.16$ & $2.15 \pm 0.23(5)$ & $2.22 \pm 0.23$ \\
\hline $\mathrm{NIC}$ & $0.60 \pm 0.14$ & $2.30 \pm 0.14$ & $2.38 \pm 0.03(4)$ & $2.45 \pm 0.03$ \\
\hline NUC & $1.13 \pm 0.01(8)$ & $2.83 \pm 0.01$ & $2.91 \pm 0.09$ (8) & $2.98 \pm 0.09$ \\
\hline OLE & $<0.1$ & & $1.37 \pm 0.06(8)$ & $1.45 \pm 0.06$ \\
\hline PAR & $<0.1$ & & $<0.5$ & \\
\hline PIC & $<0.1$ & & $<0.5$ & \\
\hline PIL & $0.74 \pm 0.09(4)$ & $2.43 \pm 0.09$ & $2.67 \pm 0.03(3)$ & $2.75 \pm 0.03$ \\
\hline PRO & $1.17 \pm 0.01(8)$ & $2.86 \pm 0.01$ & $2.96 \pm 0.14(8)$ & $3.04 \pm 0.14$ \\
\hline PTB & $<0.1$ & & $<0.5$ & \\
\hline QUI & $0.61 \pm 0.11(8)$ & $2.31 \pm 0.11$ & $2.33 \pm 0.05(8)$ & $2.40 \pm 0.05$ \\
\hline REC & $<0.1$ & & $1.63 \pm 0.01(2)$ & $1.71 \pm 0.01$ \\
\hline RET & $1.02 \pm 0.09$ & $2.72 \pm 0.09$ & $2.40 \pm 0.02(3)$ & $2.48 \pm 0.02$ \\
\hline SAT & $<0.1$ & & $<0.5$ & \\
\hline SEK & $0.14 \pm 0.09$ & $1.84 \pm 0.09$ & $2.41 \pm 0.21(6)$ & $2.49 \pm 0.21$ \\
\hline SEN & $0.89 \pm 0.10(8)$ & $2.59 \pm 0.10$ & $2.81 \pm 0.01$ & $2.88 \pm 0.01$ \\
\hline SENNO & $<0.1$ & & $<0.5$ & \\
\hline SOP & $0.45 \pm 0.07(4)$ & $2.15 \pm 0.07$ & $2.53 \pm 0.01$ & $2.60 \pm 0.01$ \\
\hline STR & $<0.1$ & & $<0.5$ & \\
\hline STY & $1.11 \pm 0.08$ & $2.81 \pm 0.08$ & $2.96 \pm 0.03(4)$ & $3.04 \pm 0.03$ \\
\hline VIN & $<0.1$ & & $2.09 \pm 0.05$ (4) & $2.16 \pm 0.05$ \\
\hline $\mathrm{YOH}$ & $0.82 \pm 0.02(4)$ & $2.52 \pm 0.02$ & NA & \\
\hline
\end{tabular}


Table 2 (continued)

$\log D_{\text {kao }}=$ sorption coefficient to kaolinite; $\log D_{\text {mont }}=$ sorption coefficient to montmorillonite; subscript CEC depicts the sorption coefficients normalized to the cation exchange capacity of the different clay minerals; values $<0.1$ or $<0.5$ are below the operational range of the method; errors are expressed by the standard deviation of experiments; numbers in parentheses = the number of individual retention measurements with quantifiable sorption coefficient for each phytotoxin; for explanation of abbreviations in column "ID" see Table $1 ; N A=$ not analyzed

Table 3 Fitting parameters for semi-quantitative isotherms describing sorption of phytotoxins to montmorillonite

\begin{tabular}{|c|c|c|c|c|c|}
\hline \multirow[t]{2}{*}{ ID } & \multicolumn{3}{|c|}{ Freundlich fit (montmorillonite) } & \multicolumn{2}{|c|}{$\begin{array}{l}\text { Linear fit } \\
\text { (montmorillonite) }\end{array}$} \\
\hline & $\log K_{F}$ & $n$ & $R^{2}$ & $\log K_{L}$ & $R^{2}$ \\
\hline $\mathrm{BIC}$ & $5.58 \pm 0.31(4)$ & $1.70 \pm 0.08$ & 1.00 & $3.04 \pm 0.13(4)$ & 0.97 \\
\hline BRU & $2.84 \pm 0.23(6)$ & $0.95 \pm 0.06$ & 0.98 & $3.03 \pm 0.12(6)$ & 0.99 \\
\hline CEV & $1.52 \pm 0.22(4)$ & $0.87 \pm 0.06$ & 0.99 & $1.96 \pm 0.01(4)$ & 0.99 \\
\hline $\mathrm{COL}$ & $1.85 \pm 0.06(4)$ & $0.93 \pm 0.02$ & 1.00 & $2.04 \pm 0.01(4)$ & 1.00 \\
\hline CYT & $2.07 \pm 0.02(4)$ & $0.97 \pm 0.01$ & 1.00 & $2.13 \pm 0.01(4)$ & 1.00 \\
\hline $\mathrm{ECH}$ & $2.02 \pm 0.44(3)$ & $0.99 \pm 0.13$ & 0.98 & $2.02 \pm 0.04(3)$ & 0.98 \\
\hline ERU & $2.66 \pm 0.01(8)$ & $0.98 \pm 0.00$ & 1.00 & $2.72 \pm 0.00(8)$ & 1.00 \\
\hline GAL & $3.07 \pm 0.03(4)$ & $1.03 \pm 0.01$ & 1.00 & $3.00 \pm 0.20(4)$ & 1.00 \\
\hline GEL & $2.29 \pm 0.05(4)$ & $0.97 \pm 0.02$ & 1.00 & $2.38 \pm 0.04(4)$ & 1.00 \\
\hline GRA & $2.84 \pm 0.20(4)$ & $1.33 \pm 0.08$ & 0.99 & $2.14 \pm 0.34(4)$ & 0.97 \\
\hline HOR & $5.09 \pm 0.26(4)$ & $2.20 \pm 0.10$ & 1.00 & $2.41 \pm 0.61$ & 0.96 \\
\hline ISC & $3.34 \pm 0.37(4)$ & & & $3.02 \pm 0.12(4)$ & 0.99 \\
\hline LAS & $2.55 \pm 0.47(6)$ & $1.07 \pm 0.14$ & 0.94 & $2.30 \pm 0.07(6)$ & 0.94 \\
\hline LYO & $1.60 \pm 0.00(4)$ & $1.01 \pm 0.00$ & 1.00 & $1.58 \pm 0.01$ & 1.00 \\
\hline MAT & $2.49 \pm 0.17(3)$ & $0.96 \pm 0.05$ & 1.00 & $2.59 \pm 0.08$ & 0.99 \\
\hline MON & $1.59 \pm 2.82(3)$ & $0.86 \pm 1.02$ & 0.42 & $1.91 \pm 0.74$ & 0.60 \\
\hline $\mathrm{NIC}$ & $2.20 \pm 0.06(4)$ & $0.93 \pm 0.02$ & & $2.34 \pm 0.30$ & 1.00 \\
\hline NUC & $4.07 \pm 0.13(8)$ & $1.33 \pm 0.04$ & 1.00 & $3.01 \pm 0.07$ (8) & 1.00 \\
\hline OLE & $0.76 \pm 0.16(8)$ & $0.81 \pm 0.05$ & 0.98 & $1.24 \pm 0.01(8)$ & 0.99 \\
\hline PIL & $2.09 \pm 0.01$ & $0.82 \pm 0.00$ & 1.00 & $2.58 \pm 0.02(3)$ & 1.00 \\
\hline PRO & $4.35 \pm 0.28(8)$ & $1.33 \pm 0.07$ & 0.99 & $3.12 \pm 0.19(8)$ & 0.90 \\
\hline QUI & $2.67 \pm 0.14(8)$ & $1.11 \pm 0.04$ & 0.99 & $2.38 \pm 0.11(8)$ & 0.99 \\
\hline RET & $2.64 \pm 0.49(3)$ & $1.07 \pm 0.13$ & 0.98 & $2.45 \pm 0.04$ & 0.98 \\
\hline SEK & $2.45 \pm 0.01(4)$ & $0.98 \pm 0.00$ & 1.00 & $2.50 \pm 0.00$ & 1.00 \\
\hline SEN & $2.84 \pm 0.11(4)$ & $1.01 \pm 0.03$ & 1.00 & $2.82 \pm 0.01(4)$ & 1.00 \\
\hline SOP & $2.43 \pm 0.03(4)$ & $0.97 \pm 0.01$ & 1.00 & $2.51 \pm 0.04$ (4) & 1.00 \\
\hline STY & $3.33 \pm 0.04$ (4) & $1.10 \pm 0.01$ & 1.00 & $3.01 \pm 0.09$ (4) & 1.00 \\
\hline VIN & $2.62 \pm 0.09$ (4) & $1.15 \pm 0.03$ & 1.00 & $2.16 \pm 0.03(4)$ & 0.99 \\
\hline
\end{tabular}

$K_{F}\left[\mathrm{mmol}^{1-\mathrm{n}} \mathrm{L}^{n} \mathrm{~kg}^{-1}\right]=$ Freundlich coefficient; $n[-]=$ Freundlich exponent; $R^{2}=$ correlation coefficient; $K_{L}\left[\mathrm{~L} \mathrm{~kg}^{-1}\right]=$ linear coefficient; numbers in parentheses specify the number of individual dilutions with quantifiable sorption coefficient for each phytotoxin

Overall, investigated concentrations corresponded to an average $c_{s}$ of $32 \mathrm{mg} \mathrm{kg}^{-1}\left(0.1 \mathrm{mmol} \mathrm{kg}{ }^{-1}\right)$ and $c_{w}$ of $2 \mathrm{mg} \mathrm{L}^{-1}\left(0.01 \mathrm{mmol} \mathrm{L}^{-1}\right)$. From an environmental relevance point of view, both these concentrations far exceeded any field observations for soil or aqueous concentrations of phytotoxins. As an example, the pyrrolizidine alkaloid ERU exhibited concentrations of
Table 4 Fitting parameters for semi-quantitative isotherms describing sorption of phytotoxins to kaolinite

\begin{tabular}{|c|c|c|c|c|c|}
\hline \multirow[t]{2}{*}{ ID } & \multicolumn{3}{|c|}{ Freundlich fit (kaolinite) } & \multicolumn{2}{|l|}{ Linear fit (kaolinite) } \\
\hline & $\log K_{F}$ & $n$ & $R^{2}$ & $\log K_{L}$ & $R^{2}$ \\
\hline $\mathrm{BIC}$ & $0.61 \pm 0.03(8)$ & $0.91 \pm 0.01$ & 1.00 & $0.85 \pm 0.06(8)$ & 1.00 \\
\hline BRU & $0.36 \pm 0.09(8)$ & $0.72 \pm 0.03$ & 0.99 & $0.93 \pm 0.45(8)$ & 0.98 \\
\hline CEV & $0.70 \pm 0.07(4)$ & $0.94 \pm 0.02$ & 1.00 & $0.85 \pm 0.46(4)$ & 0.99 \\
\hline CIN & $-0.81 \pm 0.06(4)$ & $0.61 \pm 0.02$ & 1.00 & $0.00 \pm 0.04(4)$ & 1.00 \\
\hline CYT & $0.25 \pm 0.02(8)$ & $1.00 \pm 0.01$ & 1.00 & $0.25 \pm 0.02(8)$ & 1.00 \\
\hline $\mathrm{ECH}$ & $0.06 \pm 0.05(8)$ & $0.96 \pm 0.02$ & 1.00 & $0.13 \pm 0.02(8)$ & 1.00 \\
\hline ERU & $-0.21 \pm 0.18(8)$ & $0.72 \pm 0.06$ & 0.95 & $0.40 \pm 0.23(8)$ & 0.95 \\
\hline GAL & $0.35 \pm 0.01(8)$ & $0.97 \pm 0.01$ & 1.00 & $0.36 \pm 0.01(8)$ & 1.00 \\
\hline GRA & $1.61 \pm 0.20(4)$ & $1.72 \pm 0.10$ & 0.99 & $0.44 \pm 0.36(4)$ & 0.97 \\
\hline HOR & $0.88 \pm 0.03(4)$ & $1.19 \pm 0$ & 1.00 & (4) & 1.00 \\
\hline ISC & $0.64 \pm 0.06(8)$ & $0.90 \pm 0.02$ & 1.00 & $0.84 \pm 0.08(8)$ & 1.00 \\
\hline JAC & $0.63 \pm 0.19(8)$ & $0.91 \pm 0.02$ & 0.98 & $0.92 \pm 0.45(8)$ & 0.98 \\
\hline LAS & $0.09 \pm 0.04(8)$ & $0.89 \pm 0.05$ & 1.00 & $0.31 \pm 0.04$ (8) & 1.00 \\
\hline MAT & $-0.43 \pm 0.06(8)$ & $0.57 \pm 0.02$ & 0.99 & $0.47 \pm 0.19(8)$ & 0.98 \\
\hline MON & $-0.44 \pm 0.43(4)$ & $0.67 \pm 0.21$ & 0.84 & $0.04 \pm 0.23$ & 0.92 \\
\hline $\mathrm{NIC}$ & $-0.07 \pm 0.01$ & $0.69 \pm 0.01$ & 1.00 & $0.40 \pm 0.17(4)$ & 0.99 \\
\hline NUC & $1.09 \pm 0.04(8)$ & $0.99 \pm 0.02$ & 1.00 & $1.13 \pm 0.18(8)$ & 1.00 \\
\hline PIL & $0.10 \pm 0.04$ (4) & $0.75 \pm 0.01$ & 1.00 & $0.60 \pm 0.16(4)$ & 1.00 \\
\hline PRO & $1.17 \pm 0.01(8)$ & $1.00 \pm 0.01$ & 1.00 & $1.17 \pm 0.06(8)$ & 1.00 \\
\hline QUI & $0.25 \pm 0.07(8)$ & $0.84 \pm 0.03$ & 0.99 & $0.49 \pm 0.07(8)$ & 1.00 \\
\hline RET & $0.11 \pm 0.02(4)$ & $0.72 \pm 0.01$ & 1.00 & $0.86 \pm 0.29(4)$ & 1.00 \\
\hline SEK & $-0.52 \pm 0.03$ & $0.75 \pm 0.01$ & 1.00 & $-0.01 \pm 0.06(4)$ & 0.99 \\
\hline SEN & $-0.03 \pm 0.09(8)$ & $0.71 \pm 0.03$ & 0.99 & $0.71 \pm 0.35$ & 0.97 \\
\hline SOP & $-0.03 \pm 0.01$ & $0.79 \pm 0.01$ & 1.00 & $0.33 \pm 0.07(4)$ & 1.00 \\
\hline STY & $0.41 \pm 0.03$ & $0.73 \pm 0.01$ & 1.00 & $0.96 \pm 0.58(4)$ & 0.99 \\
\hline $\mathrm{YOH}$ & $0.80 \pm 0.09$ & $0.99 \pm 0.03$ & 1.00 & $0.80 \pm 0.26(4)$ & 1.00 \\
\hline
\end{tabular}

$K_{F}\left[\mathrm{mmol}^{1-n} \mathrm{~L}^{n} \mathrm{~kg}^{-1}\right]=$ Freundlich coefficient; $n[-]=$ Freundlich exponent; $R^{2}=$ correlation coefficient; $K_{\mathrm{L}}\left[\mathrm{L} \mathrm{kg}^{-1}\right]=$ linear coefficient; numbers in parentheses specify the number of individual dilutions with quantifiable sorption coefficient for each phytotoxin

$32 \mu \mathrm{g} \mathrm{kg}^{-1}$ in topsoil and $23 \mu \mathrm{g} \mathrm{L}^{-1}$ in an adjacent pond [28]. Therefore, sorption in an even lower concentration range would be more representative for actual environmental conditions. To evaluate such concentrations, lower method detection limits would be necessary as signal intensities using DAD detection were just too low to properly differentiate peaks from background noise. Thus, presented results mainly highlight differences in sorbate behavior in general. 

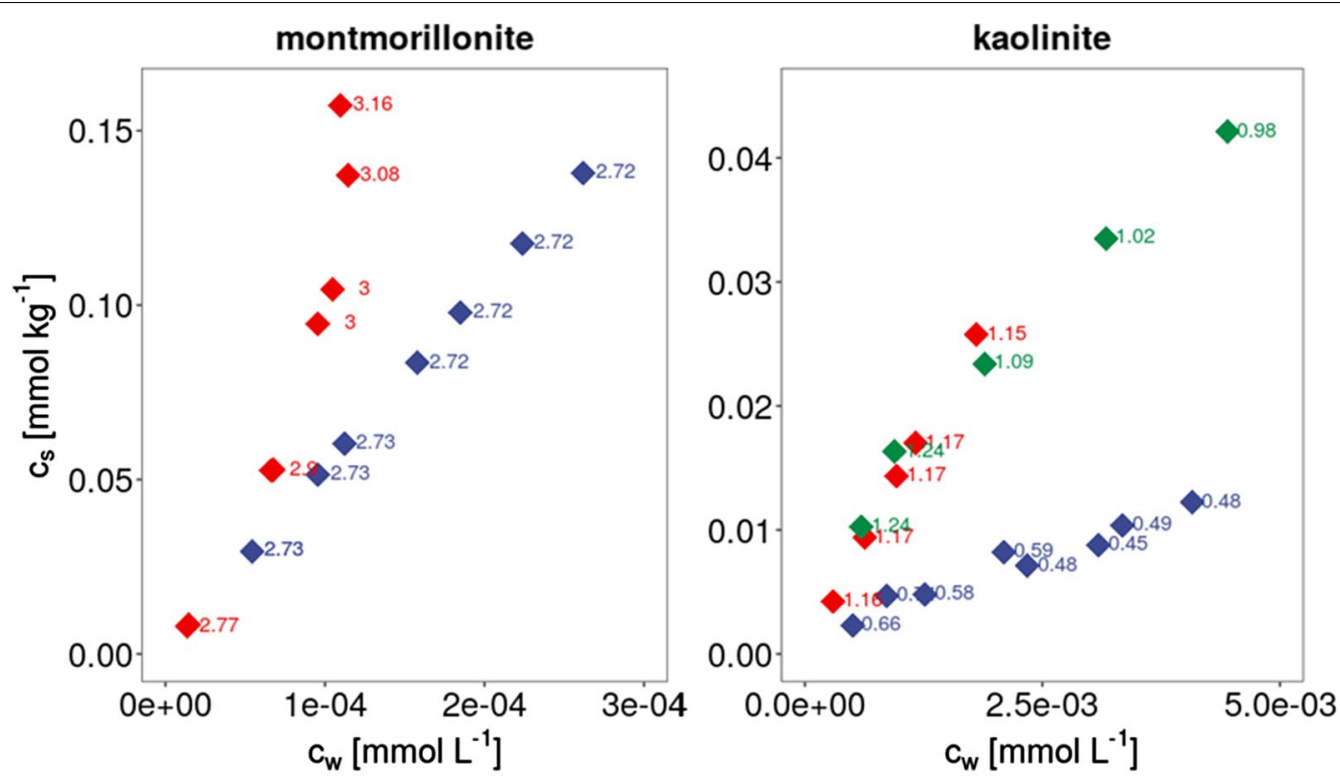

erucifoline

$\checkmark$ protopine

brucine<smiles>C/C=C1/CC(=CO)C2(C)C(=O)O[C@H]3CCN(CC=C2COC1=O)[C@H]3C</smiles><smiles>CN1CCc2cc3c(cc2C(=O)Cc2ccc4c(c2C1)OCO4)OCO3</smiles><smiles>COc1cc2c(cc1OC)N1C(=O)C[C@H]3OCC=C4CN5CC[C@]1([C@@H]43)[C@H]5C2</smiles>

Fig. 1 Sorption isotherms on clays. Numbers depict $\log D_{\text {clay }}\left[\mathrm{L} \mathrm{kg}^{-1}\right]$ for concentration pairs

Freundlich exponents $n>1$ as well as the isotherm shape shown for PRO (Fig. 1) were indicative of cooperative sorption suggesting enhanced sorbate affinities with increasing surface coverage [11, 29]. Similar ranges for $\mathrm{n}$ and sigmoidal isotherms were obtained in previous studies on cationic aromatic amines and clay minerals with interlayers in particular [29,30]. All compounds that showed this behavior in our study are rather planar, contain tertiary amine functionalities that were protonated under the experimental conditions and additionally possess aromatic moieties in proximity to the charge. It was previously suggested that intermolecular cation- $\pi-$, $\pi-\pi-$ and van der Waals interactions potentially increase sorption affinities of such cationic aromatic amines to montmorillonite clays (Fig. 2); particularly cation$\pi$-interactions were shown to predominate when just over $0.3 \%$ of cation exchange sites were occupied [29]. Based on estimated sorbed concentrations for the compounds with pronounced sorption non-linearity, experimental results presented here are still below this cutoff (e.g., $\mathrm{HOR}=0.1 \%$ ) and also below the proposed limit for sorbate-sorbate interactions of $1 \mathrm{mmol} \mathrm{kg}^{-1}$ (e.g., $\mathrm{HOR}=0.7 \mathrm{mmol} \mathrm{kg}^{-1}$ ) [11]. However, isotherms indicate that even at these low concentrations, intermolecular cation- $\pi$-interactions may occur between the $\pi$-systems of a sorbate on the clay surface and the protonated amine group of another sorbate in the vicinity (Fig. 2). To some extent the observed cooperative sorption behavior at lower percentages of cation exchange sites covered could be due to the molecular differences of the sorbates. Phytotoxins investigated in this study are structurally more complex and larger than the comparably simple previously studied aromatic substituted anilines and benzylamines [29]. This tendency may lead to an occupation of available sorption sites at lower concentrations in the case of phytotoxins. An indication for this is given by the fact that $\mathrm{N}, \mathrm{N}$-dimethylaniline already reached the range of cooperative sorption when just over $0.3 \%$ of cation exchange sites were occupied, while aniline did so only above $2.3 \%$ [29]. 


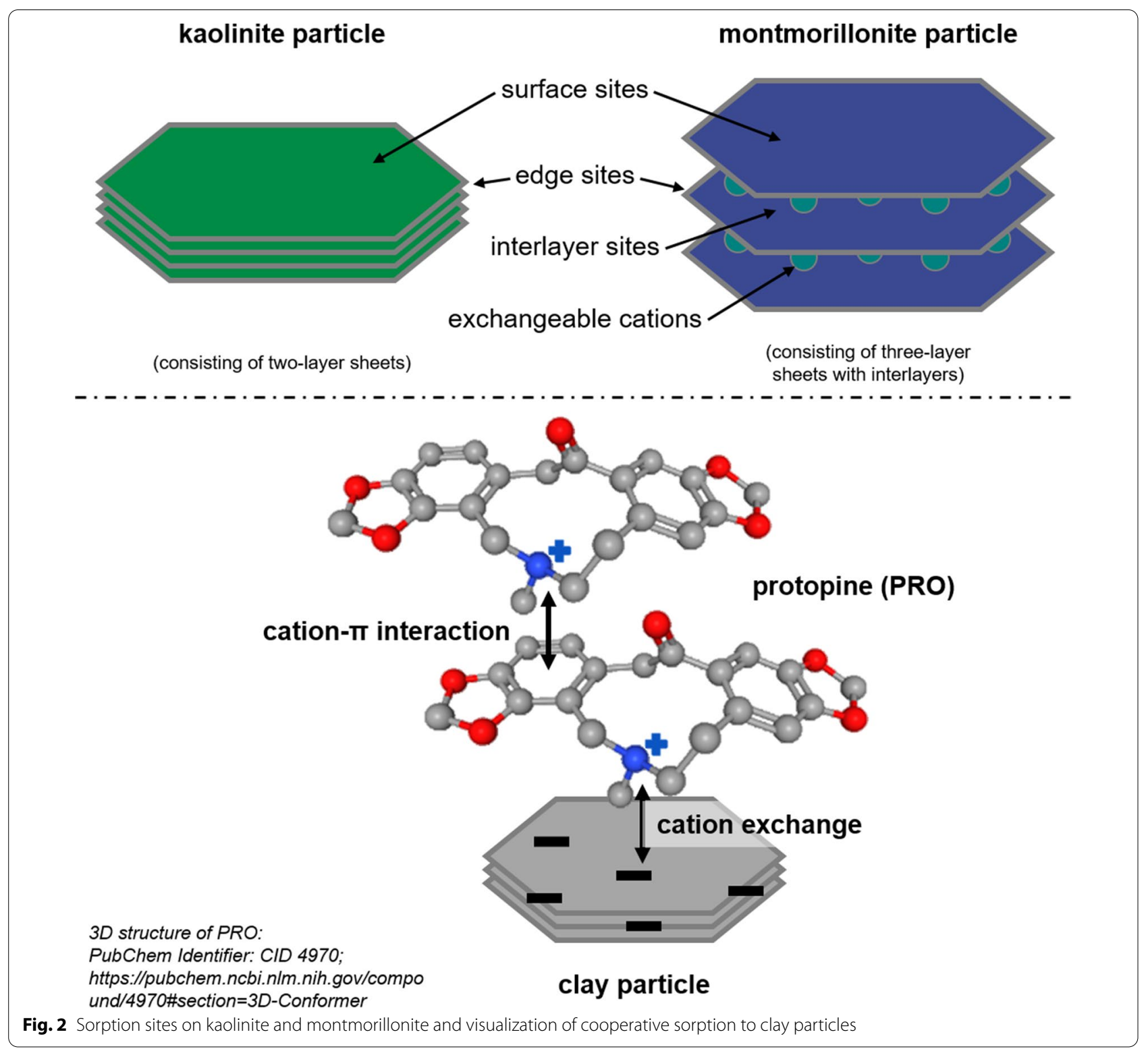

In contrast, the average Freundlich exponent for kaolinite was $n=0.87 \pm 0.03$ (Table 4) and the linear fit gave on average larger errors for the sorption coefficients than the Freundlich fit. The maximum surface coverage was reached for the amaryllidaceae alkaloid galanthamine (GAL) with $3.3 \%$, while the average coverage remained low at $0.15 \%$ (Additional file 1: Table S4). Whereas ten sorbates showed a Freundlich exponent between 0.9 and 1, indicative of linear sorption (e.g., PRO, ERU, Fig. 1), 14 out of the 26 quantified phytotoxins exhibited a Freundlich exponent below the average of 0.87 for kaolinite (Table 4). One example was the indole alkaloid brucine (BRU) depicted in Fig. 1 with an $\mathrm{n}$ of $0.72 \pm 0.03$. This pointed towards complete occupation of surface sites at higher sorbate concentrations for the clay mineral with low CEC in comparison with montmorillonite. However, GRA and HOR showed a tendency towards a sigmoidal isotherm with Freundlich exponents of $1.72 \pm 0.10$ and $1.19 \pm 0.02$ for kaolinite as well. The percentage of occupied cation exchange sites was slightly higher than for montmorillonite with, e.g., $0.1-0.5 \%$ for HOR. Thus, when exceeding a certain threshold of surface coverage, cooperative sorption could also be observed for the nonexpandable clay mineral kaolinite. This has previously only been demonstrated for 4-amino-2-methylquinoline sorption with a Freundlich exponent of $1.52 \pm 0.01$ [11]. 


\section{Normalization of clay sorption affinities to CEC}

To rule out CEC as the single driving factor of differences between kaolinite and montmorillonite sorption, obtained $\log D$ values were normalized with the respective CEC of each clay mineral. Although it was demonstrated above that sorption was not linear for several sorbates on both clays, normalization was undertaken using the average of all experimentally determined $\log D$ values for three to eight individual concentration levels (Table 2). The reason was that linear fitting gave acceptable results with average $R^{2}>0.97$ (Tables 3 and 4) for a majority of the investigated phytotoxins and over the narrow concentration ranges considered in this study. Additionally, taking linearized sorption coefficients for evaluating differences of the two clay minerals allowed direct comparison with trends observed in previous studies on structurally similar compounds [11]. This linearized data was even considered for the development of a sorption model for organic cations predicting their sorption behavior to representative soils with variations of only $-0.1 \pm 0.4 \log$ units in comparison with directly measured data [14].

As discussed above, sorption affinities of protonated phytotoxins to montmorillonite are substantially stronger than to kaolinite in accordance with the orderof-magnitude higher CEC of the former clay mineral. After normalization to CEC, the variations in $\log D$ between the two clay minerals were minimized to less than $0.5 \log$ units on average (Table 2, Fig. 3) which is in close agreement with previous studies [11]. Sorption to montmorillonite was still stronger for the majority of the compounds (Table 2, Fig. 3) and must be attributed to structural features of the clay minerals. The mineralogy of different clay minerals was shown to affect sorption behavior of organic cations, particularly for higher order amines or structurally complex sorbates [30]. It was postulated that the position of the negative charge in clay minerals may play a role in sorption of organic cations. The charge in montmorillonite predominantly originates from isomorphic substitutions in the mineral structure when clay lattice metal ions are replaced by other cations of lower charge. As about two-thirds of the negative charge are located in the internal octahedral layers of montmorillonite [31], it exhibits an electrostatic barrier for organic cation uptake [30]. In kaolinite the charge mainly results from $\mathrm{pH}$-dependent (de-)protonation of surface functional groups on edge sites (Fig. 2) [31]. Additionally, sorbates may be more constrained in sorption to interlayer sorption sites on montmorillonite which would affect structurally complex, bulky molecules in particular [30]. The only compound with a sorption affinity to kaolinite that was larger (by more than 0.5 log units) in comparison with montmorillonite after normalization is the steroidal alkaloid cevadine (CEV). With a molecular weight of $591 \mathrm{~g} \mathrm{~mol}^{-1}$ (Additional file 1: Table S1), it is the heaviest sorbate investigated on both clay minerals.

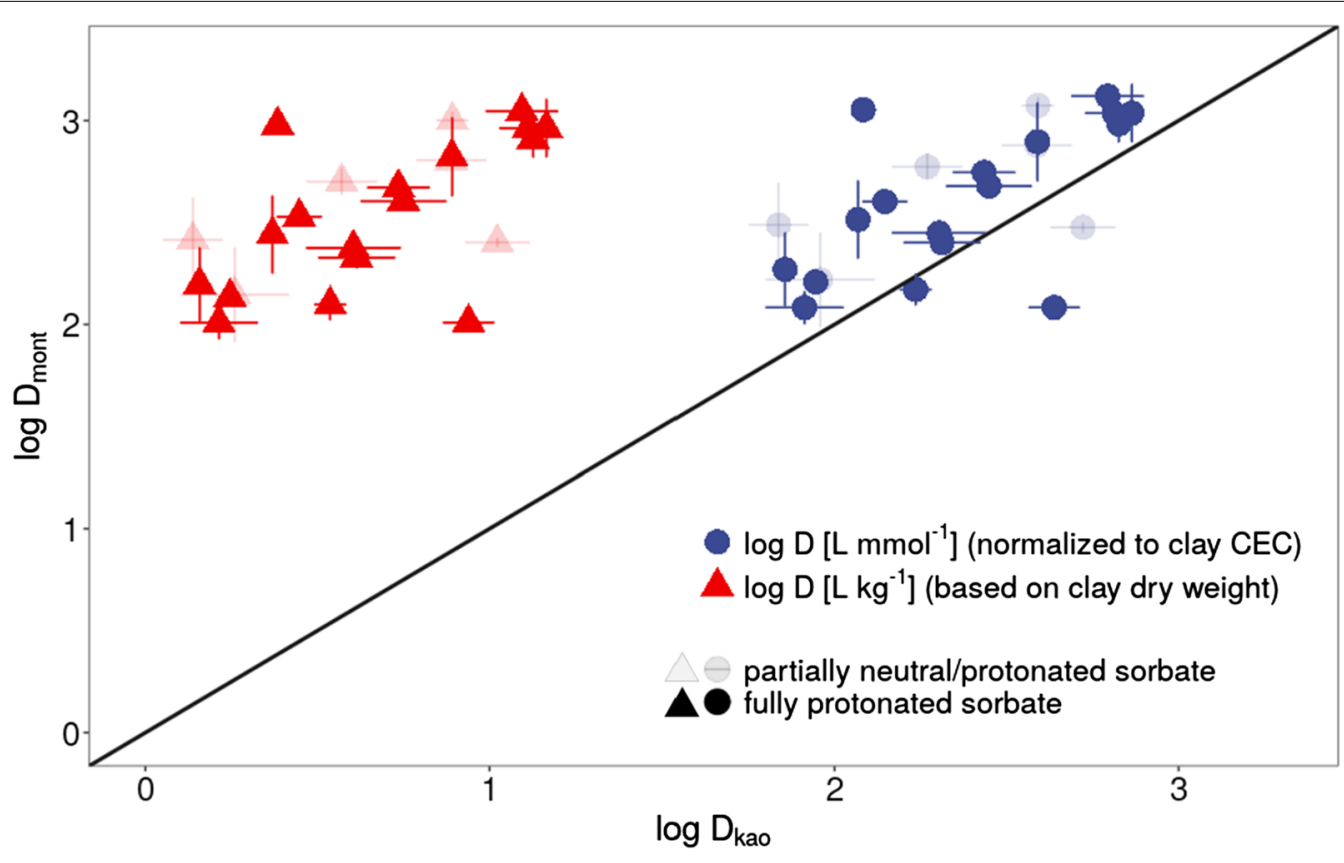

(horizontal and vertical lines depict the error bars of replicate analysis)

Fig. 3 Distribution coefficients $\log D$ for phytotoxins on kaolinite (kao) and montmorillonite (mont) 
This sorbate is almost two times heavier than the average analyte and thus potentially showed a size related restriction to sorb on (otherwise dominating) interlayer sorption sites. It was previously highlighted that the presence of various polar functional groups in addition to the protonated amine functionality mainly affects sorption to clay minerals due to sorbate size rather than polarity, thus limiting interlayer sorption [30]. The steroidal alkaloid CEV with eight polar functional groups (ester-, epoxy-, hydroxyl-groups) represents an excellent example for this observation.

Overall, the extent of sorption for structurally complex molecules with multiple functionalities to clay seems a result of the interplay of charge location and various structural features of the sorbates [30]. The set investigated here on only two clay minerals could not fully shed light on the dominating factors but stresses the need for further investigations in the processes affecting organic cation sorption to geosorbents other than SOC.

\section{Affinities of phytotoxins to clay versus soil organic carbon}

To assess the relative affinities of phytotoxins to clay compared to SOC, $D_{\text {oc }}$ of 47 compounds [12] determined with the same experimental approach were renormalized for the CEC of the organic reference material used. Out of those, 29 were quantifiable on both montmorillonite and organic carbon. Plotting experimentally derived sorption coefficients for organic carbon $\left(\log D_{\text {oc,CEC }}\right.$ ) against those for montmorillonite (Fig. 4) shows a relatively clear trend towards enhanced sorption ( $>0.5 \log$ units) for over $50 \%(n=16)$ of analyzed phytotoxins to the clay mineral. These predominantly protonated alkaloids may sorb more strongly to montmorillonite due to the potentially better accessibility of the charge on clay surfaces. Although the CEC of montmorillonite is lower in comparison with $\mathrm{SOC}[16,21]$, the nature and distribution of the charge differs markedly between the two sorbents. Firstly, montmorillonite has a high proportion of permanent charge originating from charge defects in the mineral lattice (95\%) in addition to $\mathrm{pH}$-dependent deprotonated hydroxyl-groups on edge sites. In contrast, the charge on SOC results from the deprotonation of various functional groups (e.g., carboxyl-groups) and is fully pH-dependent. Secondly, the charge is therefore more uniformly distributed over the surface of the clay while on SOC it is rather patchy and also affects the structural arrangement of the sorbent [23, 32]. Nevertheless, exceptions to this general preference for montmorillonite were noted.

Nine out of the 29 investigated phytotoxins, i.e., BRU, CEV, gelsemine (GEL), HOR, isocorydine (ISC), NUC, PRO, STY and vincamine (VIN), exhibited similar (i.e., within $0.25 \log$ units) CEC-normalized sorption coefficients to both sorbents. Excluding CEV which showed size constraints potentially hindering interlayer sorption on montmorillonite as discussed above, sorption of the other eight phytotoxins to SOC was attributed to the interplay of cation exchange and further stabilizing

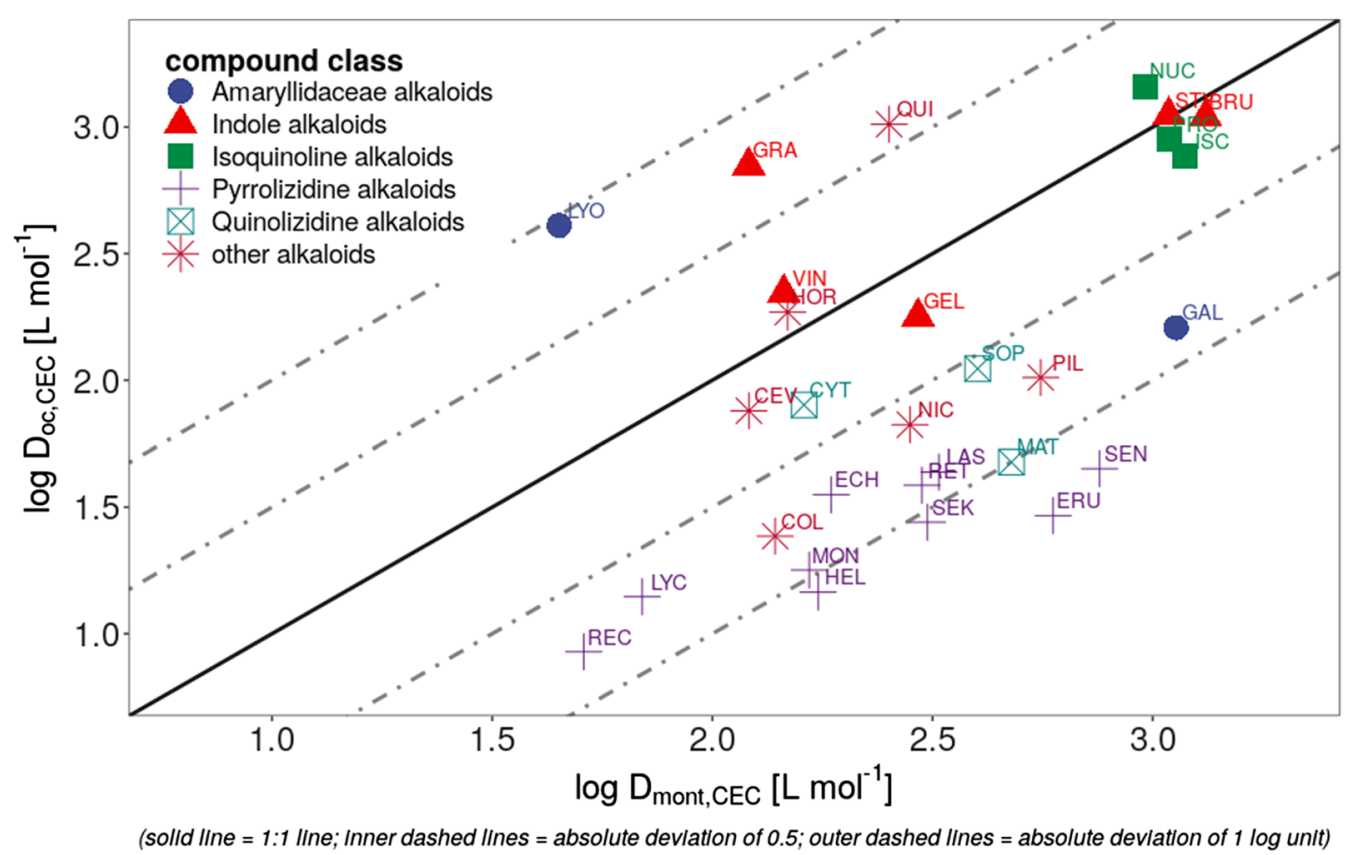

Fig. 4 CEC-normalized sorption coefficients of phytotoxins on organic carbon (oc) compared to montmorillonite (mont) 
cation- $\pi-$ or $\pi-\pi$-interactions [12]. Those stabilizing interactions may be of comparable strength to cooperative sorption demonstrated for HOR, NUC and PRO on montmorillonite. Such a similarity in interaction strength would explain the highly comparable sorption affinities to the two different geosorbents for those phytotoxins with similar structural features (protonated tertiary amines, aromatic moieties). Based on this observation, further structurally similar phytotoxins may show similar trends at higher sorbent loadings that have not been assessed for all sorbates to the same extent.

Only a few phytotoxins, lycorine (LYO), quinine (QUI) and GRA, favored sorption to SOC over that to montmorillonite with sorption coefficients 0.5 to $1 \log$ units larger for the former. The indole alkaloid GRA and the quinolone alkaloid QUI (as well as the above discussed indole alkaloid VIN) are the only N-heteroaromatics in the investigated set. In contrast to the above discussed tertiary amines with aromatic moieties that show cation- $\pi$ interactions as stabilizing processes, the $\mathrm{N}$-heteroaromatics may rather be stabilized by ternary surface complexation (i.e., including $\mathrm{Ca}^{2+}$ as a bridging cation) as suggested for structurally related benzotriazole sorption to SOC [33]. These complexation reactions are also possible for clay minerals, however, the results indicate that if they do occur for phytotoxins on montmorillonite, then at a substantially lower strength than on SOC. Additionally, protonated heteroaromatics are strong $\pi$-acceptors that are able to form $\pi-\pi$ complexes with aromatic functional groups of SOC [34-36]. Complementary $\pi$-moieties cannot be found on bare clay surfaces and thus present another explanation of the substantially weaker sorption affinities of phytotoxin $\mathrm{N}$-heteroaromatics to montmorillonite clay in comparison with SOC. The amaryllidaceae alkaloid LYO showed the in comparison strongest preference for SOC. Based on structural moieties and the observed sorption mechanisms to SOC, similar sorption affinities on clays were expected [12]. In contrast to other structurally similar phytotoxins, LYO has a significantly lower octanol-water partition coefficient $\left(K_{\text {ow }}\right)$, both based on experiments $\left(\log K_{\mathrm{ow}}=0.71 \pm 0.05\right)$ [37] and predictions (0.16) [38]. In which way this high polarity affects sorption of LYO to the clay surface but does not hinder relatively strong association with SOC functional groups remains unclear at this point. As a point of interest, the second investigated amaryllidaceae alkaloid GAL showed the exact opposite behavior with markedly enhanced sorption to montmorillonite in comparison with SOC (Fig. 4).
In general, these observations stress once more that a high proportion of organic cation sorption in soils may be assigned to clay minerals rather than organic carbon. Thus, the concept by Droge and Goss, using $\mathrm{CEC}$ correction in addition to weight fraction correction of both SOC and clay sorption coefficients in the assessment of organic cation soil sorption [14], seems reasonable. As clay fractions can far exceed the SOC fraction, depending on soil type, such an approach comes closer to real soil conditions than when assigning soil sorption of organic cations to SOC alone. A limitation is that findings cannot be always generalized for major classes of sorbates such as alkaloids for example. Instead individual compound classes have to be investigated in more detail as simple differences in molecular structures (e.g., N-heterocycles like ERU vs. $\mathrm{N}$-heteroaromatics such as GRA) lead to significantly different interactions with geosorbents.

\section{Conclusion}

The study of phytotoxin sorption affinities to clay minerals revealed the complexity in sorption of $\mathrm{N}$-containing sorbates that mainly results from their molecular features. The Freundlich fit of obtained isotherms gave good results, but concentration ranges covering several orders of magnitude should be included in future studies to confirm observed tendencies towards cooperative sorption for protonated tertiary amine phytotoxins with aromatic moieties. However, phytotoxins in soil pore water are often found in the ng $\mathrm{L}^{-1}$ to maximum low $\mu \mathrm{g} \mathrm{L}^{-1}$ concentration range [39], suggesting that higher concentration ranges are environmentally less relevant.

The exceptions presented additionally highlight that this study only provides first insights into phytotoxin clay sorption behavior and much more systematic data is needed to formulate general trends. For example, $\mathrm{X}$-ray powder diffraction measurements are a powerful technique to further elucidate specific sorption mechanisms [40] and could support future sorption studies. Further, the link between the investigated model sorbents (clay and SOC) and real aged soil constituents still needs to be clearly established, particularly in light of particle coating or aggregation. Nevertheless, the results of our study indicate that clay minerals do not enhance neutral phytotoxin sorption in soils. However, they do indeed play a role in cationic phytotoxin sorption with similar or greater sorption affinities compared to SOC. This role will particularly become relevant for phytotoxins produced by plants growing on clay rich soils. Stronger retention in soils resulting from enhanced sorption to not only SOC but in addition clay minerals would decrease phytotoxin environmental mobility. Conversely, phytotoxins sorbing strongly 
to clay minerals as well, would possess a smaller likelihood to reach water resources but may increase exposure of soil organisms instead.

\begin{abstract}
Abbreviations
SOC: Soil organic carbon; CEC: Cation exchange capacity; STY: Strychnine; SiC: Silicon carbide; $D_{\text {kao: }}$ : Distribution coefficient to kaolinite; $D_{\text {mont }}$ : Distribution coefficient to montmorillonite; DAD: Diode array detection; NIC: Nicotine; $n$ : Freundlich exponent; $K_{\mathrm{F}}$ : Freundlich coefficient; $C_{w}$ : Aqueous concentration at equilibrium; $c_{s}$ : Sorbed concentration at equilibrium; $D_{\text {kao, CEc: }}$ Cation exchange capacity normalized distribution coefficient to kaolinite; $\mathrm{D}_{\text {mont,CEC: }}$ Cation exchange capacity normalized distribution coefficient to montmorillonite; COL: Colchicine; OLE: Oleandrin; CIN: Cinobufagin; CAF: Caffeine; BIC: Bicuculline; GRA: Gramine; HOR: Hordenine; NUC: Nuciferine; PRO: Protopin; ERU: Erucifoline; BRU: Brucine; GAL: Galanthamine; CEV: Cevadine; GEL: Gelsemine; ISC: Isocorydine; VIN: Vincamine; LYO: Lycorine; QUI: Quinine; $K_{\text {ow: }}$ Octanolwater partition coefficient.
\end{abstract}

\section{Supplementary Information}

The online version contains supplementary material available at https://doi. org/10.1186/s12302-021-00469-z.

Additional file 1: Table S1. Analyzed phytotoxins and their experimental and predicted properties; Table S2. Molecular structures of all investigated phytotoxins; Table S3. Measurement wavelength, recovery and pK values of all analyzed phytotoxins; Figure $\mathbf{S 1}$. Flow rate effects on retention factor ( $k$ ) observed for the phytotoxins CAFfeine, CYTisine, GALanthamine, LYCOrine and STRophanthidin on a 1\% montmorillonite column; Figure S2. Retention time $\left(t_{R}\right)$ comparison of the non-retained tracers nitrate and thiourea (THI) on a 1\% montmorillonite column; Table S4. Maximum sorbed concentrations and the percentage of occupied cation exchange sites on both montmorillonite and kaolinite; Figure \$3. Amaryllidaceae alkaloid (GALanthamine, LYCOrine) sorption isotherms on kaolinite and montmorillonite; Figure S4. Amine (HORdenine) sorption isotherms on kaolinite and montmorillonite; Figure S5. Cardenolide and bufadienolide (CINobufagin, OLEandrin) sorption isotherms on kaolinite and montmorillonite; Figure S6. Imidazole alkaloid (PILocarpine) sorption isotherms on kaolinite and montmorillonite; Figure S7. Indole alkaloid (BRUcine, GELsemine, GRAmine, STrYchnine, VINcamine, YOHimbine) sorption isotherms on kaolinite and montmorillonite; Figure S8. Isoquinoline alkaloid (BICuculline, ISoCorydine, NUCiferine, PROtopine) sorption isotherms on kaolinite and montmorillonite; Figure S9. Pyrrolizidine alkaloid (ECHimidine, ERUcifoline, JACobine, LASiocarpine, MONocrotaline, RETrorsine, SEnKirkine, SENecionine) sorption isotherms on kaolinite and montmorillonite; Figure S10. Pyridine alkaloid (NICotine) sorption isotherms on kaolinite and montmorillonite; Figure S11. Quinoline alkaloid (QUInine) sorption isotherms on kaolinite and montmorillonite: Figure S12. Quinolizidine alkaloid (CYTisine, MATrine, SOPhocarpine) sorption isotherms on kaolinite and montmorillonite; Figure S13. Steroid alkaloid (CEVadine) sorption isotherms on kaolinite and montmorillonite; Figure S14. Tropolone alkaloid (COLchicine) sorption isotherms on montmorillonite.

\section{Acknowledgements}

The authors would like to specifically thank Inge Stockinger (Agroscope), Johanna Keita (Agroscope), Steven T. J. Droge (University of Amsterdam), Florian Metzelder and Inés Rodríguez Leal (Stockholm University) for providing assistance during setup, execution and evaluation of the experiments. ESK-SiC (Frechen, Germany) is acknowledged for donating Silicon Carbide for column experiments. Furthermore, the authors would like to show their appreciation for the continuous support by Kristopher McNeill (ETH Zürich). We also want to thank the four anonymous reviewers whose comments significantly improved our manuscript.

\section{Disclaimer}

Any opinions in this article only reflect the authors'views and the European Union's Research Executive Agency is not responsible for any use that may be made of the information it contains.

\section{Authors' contributions}

CS performed and evaluated the experiments as well as drafted the manuscript; TB and FW assisted in planning of experiments and revised the text. All authors read and approved the final manuscript.

\section{Funding}

This project received funding from the European Union's Horizon 2020 research and innovation program under the Marie Sklodowska-Curie grant agreement no. 722493 (NaToxAq).

\section{Availability of data and materials}

The complete dataset supporting the conclusions of this article is included within the article and the Electronic Supporting Information (ESI).

\section{Declarations}

\section{Ethics approval and consent to participate}

Not applicable.

\section{Consent for publication}

Not applicable.

\section{Competing interests}

The authors declare that they have no competing interests.

\section{Author details}

${ }^{1}$ Environmental Analytics, Agroscope, Reckenholzstrasse 191, 8046 Zürich, Switzerland. ${ }^{2}$ Institute of Biogeochemistry and Pollutant Dynamics, ETH Zürich, Universitätsstrasse 16, 8092 Zürich, Switzerland.

Received: 30 October 2020 Accepted: 22 February 2021

Published online: 22 March 2021

\section{References}

1. Teuscher E, Lindequist U (2010) Biogene Gifte. Wissenschaftliche Verlagsgesellschaft, Stuttgart

2. Günthardt BF, Hollender J, Hungerbühler K, Scheringer M, Bucheli TD (2018) Comprehensive toxic plants-phytotoxins database and its application in assessing aquatic micropollution potential. J Agric Food Chem 66:7577-7588

3. Wink M (2003) Evolution of secondary metabolites from an ecological and molecular phylogenetic perspective. Phytochemistry 64:3-19

4. Ames BN, Profet M, Gold LS (1990) Nature's chemicals and synthetic chemicals: Comparative toxicology. Proc Natl Acad Sci USA 87:7782-7786

5. Ames BN, Profet M, Gold LS (1990) Dietary pesticides (99.99\% all natural). Proc Nati Acad Sci USA 87:7777-7781

6. Seawright AA (1995) Directly toxic effects of plant chemicals which may occur in human and animal foods. Nat Toxins 3:227-232

7. Kookana RS, Rogers SL, Oliver DP (1997) Sorption and desorption behaviour of strychnine rodenticide in soils. Aust J Soil Res 35:491-502

8. Gimsing AL, Poulsen JL, Pedersen HL, Bruun Hansen HC (2007) Formation and degradation kinetics of the biofumigant benzyl isothiocyanate in soil. Environ Sci Technol 41:4271-4276

9. Wink M (2009) Mode of action and toxicology of plant toxins and poisonous plants. Mitt Julius Kühn Inst 421:93-112

10. MacKay AA, Vasudevan D (2012) Polyfunctional ionogenic compound sorption: challenges and new approaches to advance predictive models. Environ Sci Technol 46:9209-9223

11. Droge ST, Goss KU (2013) Sorption of organic cations to phyllosilicate clay minerals: CEC-normalization, salt dependency, and the 
role of electrostatic and hydrophobic effects. Environ Sci Technol 47:14224-14332

12. Schönsee CD, Wettstein FE, Bucheli TD (2021) Disentangling mechanisms in natural toxin sorption to soil organic carbon. Environ Sci Technol. https://doi.org/10.1021/acs.est.0c06634

13. Tolls J (2001) Sorption of veterinary pharmaceuticals in soils: a review. Environ Sci Technol 35:3397-3406

14. Droge ST, Goss KU (2013) Development and evaluation of a new sorption model for organic cations in soil: contributions from organic matter and clay minerals. Environ Sci Technol 47:14233-14241

15. Starr RI, Timm RW, Doxtader KG, Hurlbut DB, Volz SA, Goodall M (1996) Sorption and aerobic biodegradation of strychnine alkaloid in various soil systems. J Agric Food Chem 44:1603-1608

16. The Clay Minerals Society (2019) http://clays.org/sourceclays_data.html. Accessed 14th Jun 2020

17. Bronner G, Goss KU (2011) Predicting sorption of pesticides and other multifunctional organic chemicals to soil organic carbon. Environ Sci Technol 45:1313-1319

18. Jolin WC, Sullivan J, Vasudevan D, MacKay AA (2016) Column chromatography to obtain organic cation sorption isotherms. Environ Sci Technol 50:8196-8204

19. Metzelder F, Schmidt TC (2017) Environmental conditions influencing sorption of inorganic anions to multiwalled carbon nanotubes studied by column chromatography. Environ Sci Technol 51:4928-4935

20. Valocchi AJ (1985) Validity of the local equilibrium assumption for modeling sorbing solute transport through homogeneous soil. Water Resour Res 21:808-820

21. Lyon WG (1995) Swelling of peats in liquid methyl, tetramethylene and propyl sulfoxides and in liquid propyl sulfone. Environ Toxicol Chem 14:229-236

22. Schenzel J, Goss KU, Schwarzenbach RP, Bucheli TD, Droge ST (2012) Experimentally determined soil organic matter-water sorption coefficients for different classes of natural toxins and comparison with estimated numbers. Environ Sci Technol 46:6118-6126

23. Schwarzenbach RP, Gschwend PM, Imboden DM (2003) Environmental organic chemistry. Wiley-Interscience, Hoboken, New Jersey, US

24. Bi E, Schmidt TC, Haderlein SB (2010) Practical issues relating to soil column chromatography for sorption parameter determination. Chemosphere 80:787-793

25. Bi E, Schmidt TC, Haderlein SB (2006) Sorption of heterocyclic organic compounds to reference soils: column studies for process identification. Environ Sci Technol 40:5962-5970

26. Gawlik BM, Feicht EA, Karcher W, Kettrup A, Muntau H (1998) Application of the European Reference Soil Set (EUROSOILS) to a HPLC-screening method for the estimation of soil adsorption coefficients of organic compounds. Chemosphere 36:2903-2919
27. Samaraweera M, Jolin W, Vasudevan D, MacKay AA, Gascón JA (2014) Atomistic prediction of sorption free energies of cationic aromatic amines on montmorillonite: a linear interaction energy method. Environ Sci Technol Lett 1:284-289

28. Hama JR, Strobel BW (2019) Pyrrolizidine alkaloids quantified in soil and water using UPLC-MS/MS. RSC Adv 9:30350-30357

29. Vasudevan D, Arey TA, Dickstein DR, Newman MH, Zhang TY, Kinnear HM, Bader MM (2013) Nonlinearity of cationic aromatic amine sorption to aluminosilicates and soils: role of intermolecular cation $-\pi$ interactions. Environ Sci Technol 47:14119-14127

30. Jolin WC, Richard A, Vasudevan D, Gascon JA, MacKay AA (2020) Aluminosilicate mineralogy and the sorption of organic cations: interplay between electrostatic barriers and compound structural features. Environ Sci Technol 54:1623-1633

31. Matocha CJ (2016) Clay minerals: charge properties. In: Encyclopedia of soil science, CRC Press, Boca Raton

32. Rowley MC, Grand S, Verrecchia ÉP (2017) Calcium-mediated stabilisation of soil organic carbon. Biogeochemistry 137:27-49

33. Bi E, Schmidt TC, Haderlein SB (2007) Environmental factors influencing sorption of heterocyclic aromatic compounds to soil. Environ Sci Technol 41:3172-3178

34. Wijnja H, Pignatello JJ, Malekani K (2004) Formation of $\pi-\pi$ complexes between phenanthrene and model $\pi$-acceptor humic subunits. J Environ Qual 33:265-275

35. Hunter CA, Lawson KR, Perkins J, Urch CJ (2001) Aromatic interactions. J Chem Soc Perkin Trans 2:651-669

36. Zhu D, Hyun S, Pignatello JJ, Lee LS (2004) Evidence for $\pi-\pi$ electron donor-acceptor interactions between $\pi$-donor aromatic compounds and $\pi$-acceptor sites in soil organic matter through $\mathrm{pH}$ effects on sorption. Environ Sci Technol 38:4361-4368

37. Schönsee CD, Bucheli TD (2020) Experimental determination of octanolwater partition coefficients of selected natural toxins. J Chem Eng Data 65:1946-1953

38. ChemAxon (2019) Chemicalize (https://chemicalize.com/), ChemAxon Ltd., Budapest

39. Hama JR, Strobel BW (2020) Natural alkaloids from narrow-leaf and yellow lupins transfer to soil and soil solution in agricultural fields. Environ Sci Eur. https://doi.org/10.1186/s12302-020-00405-7

40. Nowara A, Burhenne J, Spiteller M (1997) Binding of fluoroquinolone carboxylic acid derivatives to clay minerals. J Agric Food Chem 45:1459-1463

\section{Publisher's Note}

Springer Nature remains neutral with regard to jurisdictional claims in published maps and institutional affiliations.

\section{Submit your manuscript to a SpringerOpen ${ }^{\circ}$ journal and benefit from:}

- Convenient online submission

- Rigorous peer review

- Open access: articles freely available online

- High visibility within the field

- Retaining the copyright to your article

Submit your next manuscript at $\boldsymbol{\nabla}$ springeropen.com 